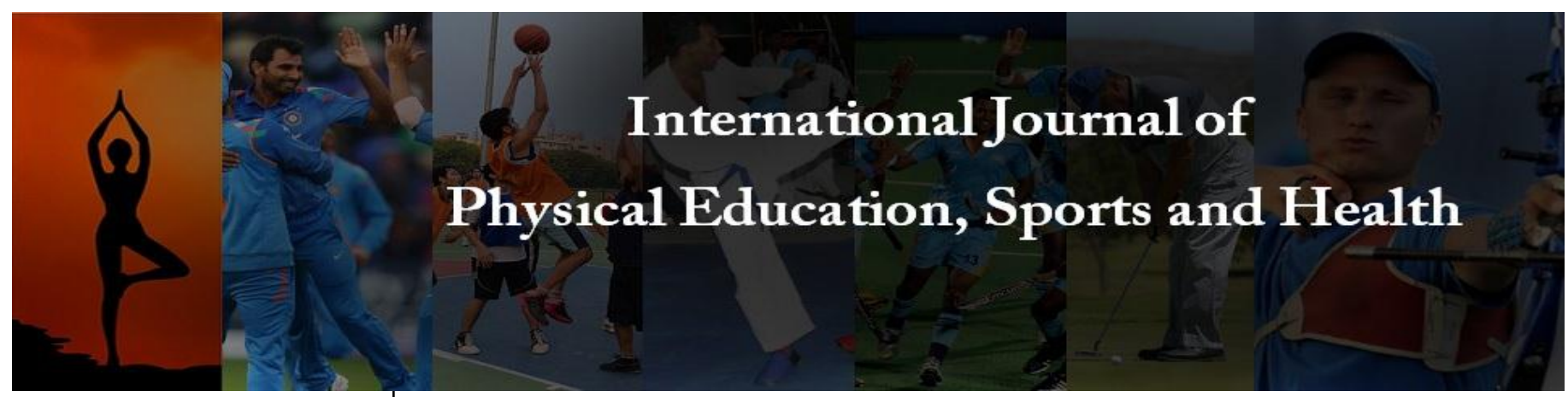

P-ISSN: 2394-1685

E-ISSN: 2394-1693

Impact Factor (ISRA): 5.38

IJPESH 2022; 9(1): 259-262

(C) 2022 IJPESH

www.kheljournal.com

Received: 19-10-2021

Accepted: 02-12-2021

Chander Shekhar Datta

Ph. D Research Scholar,

Department of Physical

Education, Kalinga University,

Naya Raipur, Chhattisgarh,

India

\section{Atul Shukla}

Assistant Professor, Department of Physical Education, Kalinga

University, Naya Raipur,

Chhattisgarh, India

\section{Pawan Kumar}

Department of Physical

Education, Bhaskaracharya

College of Applied Sciences,

University of Delhi, Dwarka,

New Delhi, India
Corresponding Author: Chander Shekhar Datta Ph. D Research Scholar, Department of Physical Education, Kalinga University, Naya Raipur, Chhattisgarh, India

\section{Comparison between pre test and post test in regard to selected parasympathetic reactivity variable of male football players}

\author{
Chander Shekhar Datta, Atul Shukla and Pawan Kumar
}

\section{Abstract}

The objective of the study was to compare between Pre Test and Post Test in regard to selected parasympathetic reactivity variable of male football players age ranging from 18 to 25 years. Hence, after the pre-test the vigorous football training (treatment variables) and post-test after the vigorous football training for six months were conducted to collect the data on selected parasympathetic reactivity variable namely expiratory inspiratory ratio (beats/minute). To test the effect of vigorous training on football layers the test retest design was adopted, for comparison between the data collected at pre-test and posttest, the collected data needed to be described. Hence, the mean and standard deviation (SD) were selected as descriptive statistics. Thereafter the comparison between pre-test and post-test of selected parasympathetic reactivity variables have been done by computing ' $t$ ' test. The drawn hypothesis was tested at 0.05 level of significance. The samples of the study were 30 ( 15 pre and 15 post-test). For 6 cycles per minute, the inspiration was done for 5 seconds, and expiration for 5 seconds. If cycles were not appropriately done, it was repeated again in order to get 6 complete cycles (i.e. each cycle consisting of 5 seconds inspiration following by 5 seconds expiration). At pre, and post-test expiratory inspiratory ratio (beats/ minute) have $1.31 \pm 0.17$ and $1.30 \pm 0.19$ as mean and standard deviation respectively. The calculated ' $t$ ' of expiratory inspiratory test (beats/minute) was 12.20 which was significantly different at 0.5 level with mean difference (MD) of 0.05 where the mean value decreased from pre-test to post-test. The selected variables collectively which demonstrated the positive effect of vigorous football training in regard to selected parasympathetic reactivity variable of male football players.

Keywords: Expiratory, inspiratory, pre-test, post-test

\section{Introduction}

Physical fitness is one of the most important aspects of Football performance. A skilful player will go along way in the sport, but without the fitness part of their game they will not be the complete player. Aerobic endurance fitness is one of the most important physical fitness attributes for soccer players. Players need to be able to maintain a high level of intensity throughout the 90-minute game. Another very important fitness component is anaerobic fitness, which means running speed and particularly repeat sprint ability. Players also need good agility, strength, power and flexibility.

Autonomic nervous system through its limbs, the sympathetic and parasympathetic nervous system controls the visceral function of the human body. Autonomic nervous system controls working of heart during exercise. It is known that increase in heart rate during mild to moderate level of exercise is due to the withdrawal of Parasympathetic Nervous System activity. The rise in heart rate during strenuous exercise is mediated through sympathetic activity.

The regular exercise leads to adaptive changes in cardiac and physical performance and autonomic responses. Physical training leads to reduction in intrinsic rate. Physically trained individuals are found to have changed parasympathetic activity and perhaps reduced sympathetic activity. Many studies confirm alteration in autonomic activity with physical training but studies on effect of physical training on autonomic reactivity are rare. It is a possibility that along with activity, reactivity is also altered. Perhaps the two can very independently, although no evidence is available to support this fact. It may be true that physical training influences autonomic parameters, the contrary may also be true, that is initial 
levels of autonomic parameters may substantially influence outcome of physical training.

If one had a normal core temperature a normal cardiac condition system and the electrolyte homeostasis, it is reasonable to assume that resting HR would be a function of intrinsic HR and the net influence of the parasympathetic and sympathetic NS. Therefore, changes in the intrinsic heart rate, resting parasympathetic and sympathetic activity or the balance of parasympathetic and sympathetic activity would affect the resting HR. Out of all the physiological conditioning exercise, of a strenuous nature, has the most powerful effect upon the B.P. (Blood pressure) has been used as a strong measure for examining the functioning of Cardio Vascular System in the human body. The increase and the decrease of the HR of well trained subjects at the beginning and immediately after the exercise are much faster and rapid than those of untrained subjects. In untrained subjects, while the BP responds very little but the HR responds sharply to exercise in trained subjects.

\section{Hypothesis}

It was hypothesized that there will be positive effect of vigorous football training on the selected parasympathetic reactivity variable of football players between pre-test and post-test aged between 18 years to 25 years.

\section{Materials and Methodology \\ Selection of Subjects}

1. Keeping in view the purpose of the study 15 (fifteen) male football players of University of Delhi were selected. $\left(\mathrm{N}=30\right.$ i.e., at pre test $\mathrm{n}_{1}=15$ and at post test $\mathrm{n}_{2}$ $=15$ )

2. The age of the subjects ranged from 18 years to 25 years.

3. 15 subjects were recorded thrice at Pre-Test as well as at Post-Test and then the recorded test scores were averaged hence; data samplings were 45 each for pre test and post test.

Selection of Variables: The research scholar gleaned through the available scientific literature from physiology, sports medicine, journals, magazines and periodicals etc. Keeping in view the feasibility criteria, availability of the instruments and purpose of the study, following variables was selected:

- Expiratory Inspiratory Ratio (beats/minute)

\section{Reliability of Data}

- The investigator had under gone a special training under the guidance of an expert for measuring and recording the blood pressure, height, weight and heart rate, expiratory inspiratory ratio (beats/minute), (beats/minute) and the proper use of various physiological equipments.

- After training and being acquainted with the use of various equipments, testing devices, number of subjects were examined and measured to test the reliability and competency of the research scholar before actual data collection for the study.

\section{Reliability of Instruments}

The latest scientific instruments and devices, imported, installed and calibrated by the International level companies. Before starting the test, the equipments were also calibrated.

\section{Administration of the Tests and Collection of Data}

The study was conducted at University of Delhi. The subject visited the laboratory on the dates and times given to them.
The following instructions were given to the subject in advance:

1. No consumption of tea, coffee or other caffeinated beverages at least, two hours before the recording.

2. No consumption of food stuff, two hours before the recording.

3. No use of medicines 24 hours before the recording.

Expiratory Inspiratory Ratio (EIR)

\begin{tabular}{|c|c|}
\hline Stimulus & $\begin{array}{c}\text { Deep and regular breathing at the rate of 6 breaths } \\
\text { per minute }\end{array}$ \\
\hline Afferents & Central \\
\hline Efferent & Parasympathetic (cardio vagal, cholinergic) \\
\hline $\begin{array}{c}\text { Normal } \\
\text { Response: }\end{array}$ & $\begin{array}{c}\text { Increase in heart rate with inspiration and decrease } \\
\text { in heart rate with expiration. }\end{array}$ \\
\hline
\end{tabular}

\section{Protocol}

The subject was instructed about the test. It was explained that breathing should be smooth, slow and deep. The investigator gave the hand signal to maintain the rate and timing of the breathing. For 6 cycles per minute, the inspiration was done for 5 seconds, and expiration for 5 seconds. If cycles were not appropriately done, it was repeated again in order to get 6 complete cycles (i.e. each cycle consisting of 5 seconds inspiration following by 5 seconds expiration).

\section{Recording}

A baseline recording of ECG and respiration was taken for 30 seconds. After that deep breathing test was started and recording of respiration and ECG was continued throughout the test. Calculation was done from the tracing of respiration and ECG.

\section{Calculations}

a. E: I ratio of the longest R-R interval and shortest R-R interval averaged over 6 cycles.

\section{Normal values}

$\mathrm{E}: \mathrm{I}$ ratio $\geq 1.21$ normal

\section{Physiological basis of the test}

The variation of heart rate with respiration often known as sinus arrhythmia is primarily mediated by the vagal innervations of the heart. The neuronal output from the respiratory centre influences the gain of the afferent and efferent outputs at the nucleus tractus solitarius. Pulmonary stretch receptors as well as cardiac mechanoreceptors and possibly baroreceptors contribute in the regulation of heart rate variation.

It decreases with age, hyperventilation and hypocapnia, increasing resting heart rate. It also decreases in cardiac failure, pulmonary disease and CNS depression.

In patients with autonomic failure syndromes such as multiple system atrophy and progressive autonomic failure, abnormalities are detected in $80-85 \%$ of patients

\section{Precautions}

a) Signal should be given properly so that inspiratory and expiratorty phase of each respiratory cycle can be maintained for 5 seconds.

b) Breathing of the subject should be slow, smooth and deep which can be confirmed from the respiratory tracing while doing the test.

c) If cycles are not appropriately done, it is repeated again 
in order to get 6 complete cycles (i.e. each cycle consisting of 5 seconds inspiration followed by 5 seconds expiration).

d) Test should not be conducted in patients with acute respiratory disease.

\section{Statistical Procedure}

The data obtained was analyzed by computing the following statistics: Mean, Standard Deviation (SD), A two tail ' $t$ ' test by difference method was applicable to these paired observations of a single- group experiment. $\mathrm{H}_{0}$ proposes that there is no significant difference between the paired observations; any observed difference being due to the chance alone. In the present study the research hypothesis was tested by using the following formula:

$$
\mathrm{t}=\frac{\Sigma \mathrm{D}}{\sqrt{\frac{\mathrm{N} \Sigma \mathrm{D}^{2}-(\Sigma \mathrm{D})^{2}}{\mathrm{~N}-1}}}
$$

Where,

N-Sample size; $\Sigma \mathrm{D}$ - Sum total of differences between pre-test and post-test of selected parasympathetic reactivity variable; $\Sigma \mathrm{D}^{2}$ - Sum total of square of differences between pre-test and post-test of selected parasympathetic reactivity variable; $(\Sigma \mathrm{D})^{2}$ - Whole square of sum total of differences between pre-test and post-test selected of parasympathetic reactivity variable.

The level of significance chosen was 0.05 for testing the hypothesis

\section{Results}

Table 1: Descriptive Statistics of Selected Parasympathetic Reactivity Variable Recorded at Pre Test of Male Football layers

\begin{tabular}{|c|c|c|c|c|c|}
\hline S. No. & Variables & Mean & SD & Max. Score & Min. Score \\
\hline 1 & Age (years) & 21.00 & 1.92 & 25 & 19 \\
\hline 2 & Weight (kilogram) & 62.54 & 9.35 & 81 & 50 \\
\hline 3 & Height (centimeter) & 167.54 & 9.23 & 182 & 152 \\
\hline 4 & Expiratory Inspiratory Ratio (beats/minute) & 1.31 & 0.17 & 1.61 & 1.02 \\
\hline
\end{tabular}

Sample size $\left(\mathrm{n}_{1}\right)-13$; SD- Standard Deviation; Min. Score- Maximum Score; Max. Score - Minimum Score

The table 1 documents the mean, standard deviation (SD), maximum score and minimum score of age (year), weight (kilogram), height (centimeter), expiratory inspiratory ratio, valsalva ratio and 30:15 ratio recorded at pre test. according to table 1 age (year) have $21 \pm 1.92$ as mean and standard deviation; likely weight (kilogram) have $62.54 \pm 9.35$ as mean and standard deviation; height (centimeter) have $167.54 \pm$ 9.23 as mean and standard deviation; expiratory inspiratory ratio (beats/ minute) have $1.31 \pm 0.17$ as mean and standard deviation.

Table 2: Descriptive Statistics of Selected Parasympathetic Reactivity Variable Recorded at Post Test of Male Football Players

\begin{tabular}{|c|c|c|c|c|c|}
\hline S. No & Variables & Mean & SD & Max. Score & Min. Score \\
\hline 1 & Age (years) & 21.27 & 2.02 & 25 & 19 \\
\hline 2 & Weight (kilogram) & 64.27 & 9.86 & 84 & 50 \\
\hline 3 & Height (centimeter) & 168.87 & 7.83 & 182 & 158 \\
\hline 4 & Expiratory Inspiratory Ratio (beats/minute) & 1.30 & 0.19 & 1.60 & 0.76 \\
\hline
\end{tabular}

Sample size (n2- 15; SD - Standard Deviation; Min. Score- Maximum Score; Max. Score - Minimum Score

The table 2 documents the mean, standard deviation (SD), maximum score and minimum score of age (year), weight (kilogram), height (centimeter), expiratory inspiratory ratio, valsalva ratio and 30:15 ratio recorded at post test. according to table 2 age (year) have $21.27 \pm 2.02$ as mean and standard deviation (SD), likely weight (kilogram) have $64.27 \pm 9.86$ as mean and standard deviation; height (centimeter) $168.87 \pm$ 7.83 as mean and standard deviation (SD), as mean and standard deviation; expiratory inspiratory ratio (beats/minute) have $1.30 \pm 0.19$ as mean and standard deviation (SD).

Table 3: Comparison between Pre Test and Post Test in Regard to Selected Parasympathetic Reactivity Variables of Male Football Players

\begin{tabular}{|c|c|c|c|c|c|c|c|c|c|}
\hline S. No. & Variables (Beats/minute) & Test & Mean & SD & MD & SED & $\sum$ D & $\sum \mathbf{D}^{\mathbf{2}}$ & $\mathbf{t}^{\prime}$ Ratio \\
\hline 1 & EIR & Pre Test & 1.35 & 0.15 & \multirow{2}{*}{0.05} & \multirow{2}{*}{0.08} & \multirow{2}{*}{1.66} & 0.42 & \multirow{2}{*}{$12.20 *$} \\
\hline
\end{tabular}

* Significant at 0.05 level of significant; Sample Size $(\mathrm{N})-\left(\mathrm{n}_{1}+\mathrm{n}_{2}=22\right)$; SD- Standard Deviation; MD- Mean differences between pre test and post test of selected parasympathetic reactivity variables; SED- Standard error of differences between pre test and post Test of selected parasympathetic reactivity variables; $\sum \mathrm{D}$ - Sum total of differences between pre test and post test of selected parasympathetic reactivity variables; $\sum \mathrm{D}^{2}$ - Sum total of square of differences between pre-test and post-test of selected parasympathetic reactivity variables; EIRExpiratory Inspiratory Ratio (beats/minute

\section{Discussion}

The analysis of the data in table-3 documented that the calculated ' $t$ ' of expiratory inspiratory test (beats/minute) was 12.20 which was significantly different at 0.5 level with mean difference (MD) of 0.05 where the mean value decreased from pre-test to post-test. The selected variables collectively which demonstrated the positive effect of vigorous football training in regard to selected parasympathetic reactivity variables of male football players. The findings have been graphically illustrated in figure 1 , which demonstrated the positive effect of football training in regard to selected parasympathetic reactivity variables of male football players.

\section{Discussion of Findings}

Autonomic Nervous System through its branches, sympathetic nervous system and parasympathetic nervous system, control the visceral functions of the human body. Almost all the functions of the cardio- vascular system are regulated or modulated by the autonomic system.

It was hypothesized that there will be positive effect of 
vigorous football training on the selected parasympathetic reactivity variables of football players age ranging 18- 25 years. The analysis of the data in table- 3 documented that the calculated ' $t$ ' of expiratory inspiratory test (beats/minute) was 12.20 which was significantly different at 0.5 level with mean difference (MD) of 0.05 where the mean value decreased from pre-test to post-test. The selected variables collectively which demonstrated the positive effect of vigorous football training in regard to selected parasympathetic reactivity variables of male football players. The findings have been graphically illustrated in figures from 1 to 2 , which demonstrated the positive effect of vigorous football training in regard to selected parasympathetic reactivity variable of male football players. Hence, accepted the drawn hypothesis at 0.05 level of significance. But it should be noted that none of the above study was conducted on football hence, the present experimentation is an addition to existing book of knowledge.

\section{References}

1. Adams AD, Victor M. Disorders of the Autonomic Nervous System: Principles of Neurology (New York: McGraw-Hill. Inc.), 1993, pp.457-79.

2. Leblance AJ. "Use of Heart Rate as an Index of Work Output”, J Appl. Physiol. 1975;10.5:275-80.

3. Ekblom B, Astrand PO, Satten B, Stenberg J, Wallstorm B. "Effects of Training on Circulatory Response to Exercise", J APPL. Physiol. 1968;24:518-28.

4. Donald B, Kinbom A, Soloysaik J. "Physical Training, Bradycardia and Autonomic Nervous System", Scand J. Clin. 1973;32:251-256.

5. Cardiovascular Autonomic Function Testing: principles and methods. Autonomic Function Lab, Department of Physiology. All India Institute of Medical Sciences AIIMS New Delhi 29.

6. Dhananjoy Shaw Fundamental Statistic in Physical Education and Sports Sciences (New Delhi: Sport Publication), 1998, pp. 108-109.

7. https://www.topendsports.com/sport/soccer/fitness.htm

8. Astrand PO, Cudy TE, Stenberg J. "Cardiac Output During Sub-Maximal and Maximal Work”, J Appl. Physiol. 1984;19:268-277.

9. Stewen Leqis F. "Non Autonomic Component in Bradycardia of Endurance Trained Men At Rest and During Exercise", Acta Physical Scand 1980;109:297305. 